\title{
Effect of Nimodipine (0.5\%) Eye Drops Against Selentie-Induced Cataract in Rabbits
}

\author{
Dalia A. Shakoor ${ }^{1}$ MSC, Adeeb A. Al-Zubaidy ${ }^{2} P h D$, Ban J. Qasim ${ }^{3}$ PhD \\ ${ }^{1}$ Dept. of Pharmacology and Toxicology, College of Pharmacy, University of Mustansiriyah, Baghdad, Iraq; , ${ }^{2}$ Dept. of \\ Pharmacology and Toxicology, College of Pharmacy, Al-Nahrain University, Baghdad, Iraq, ${ }^{3}$ Dept. of Pathology, College \\ of Medicine, Al-Nahrain University, Baghdad, Iraq
}

\begin{abstract}
Background Increase $\mathrm{Ca}^{2+}$ level in human lenses found to play a main role in the opacification development.

Objective To investigate the protective effects of nimodipine $(0.5 \%)$ eye drops against selenite-induced cataract in rabbits.

Methods Twenty-four adult rabbits with body weight in a range of $(1.5-2 \mathrm{~kg})$ with no signs of ocular inflammation were divided into three groups (apparently normal group, cataract group, nimodipine (0.5\%) eye drops group). Cataract induction was done by a single intravitreal injection of sodium selenite solution in right eye. Lens opacity, pupil diameter, intraocular pressure, pupillary response to light, corneal sensation, conjunctival redness, malondialdehyde (MDA) and reduced glutathione (GSH) levels in aqueous humor and histopathological study of lens were evaluated. Apparently, normal group received distilled water.

Results Nimodipine (0.5\%) eye drops resulted in prevention of cataract development, there was no change in pupil diameter, positive pupillary response to light, positive corneal sensation, no conjunctival redness, decreased MDA and increased of GSH levels. Longitudinal lens section showed homogenous appearance and it looked like normal in its feature.

Conclusions Nimodipine (0.5\%) eye drops had prophylactic effect against selenite-induced cataract in rabbits.

Key words Cataract, nimodipine, selenite.
\end{abstract}

List of abbreviation: MDA = malondialdehyde, $\mathrm{GSH}=$ reduced glutathione, IOP = intraocular pressure, FFA = free fatty acids

\section{Introduction}

ataract is an opaqueness of the lens which leads to decreased visual acuity ${ }^{(1)}$. Cataract becomes more common with advanced age and it is one of the chief causes of blindness and visual impairment in elderly people throughout the developing world ${ }^{(2)}$. So, detection of factors that might delay or prevent cataract occurrence would be essential both for increasing the well-being of elderly and for decreasing medical care costs. Many factors; such as genetics, cigarette smoking and sunlight exposure are implicated in the progression of lens opacity ${ }^{(3,4,5)}$. Specifically, oxidative stress is thought to have a major role in the etiology of age-related cataract ${ }^{(6)}$. Nimodipine is a member of the dihydropyridine group of calcium channel blockers, which has a high affinity for the cerebral blood vessels and appears to decrease morbidity following a subarachnoid hemorrhage ${ }^{(7,8)}$.

The aim of this study was to investigate the protective effects of nimodipine $(0.5 \%)$ eye drops against selenite-induced cataract in rabbits. 


\section{Methods}

Twenty-four adult rabbits with body weight in a range of $(1.5-2 \mathrm{~kg})$ with no signs of ocular inflammation were divided into three groups (apparently normal group, cataract group and nimodipine $(0.5 \%)$ eye drops group). The rabbits were housed in Animal House of High Institute for Infertility Diagnosis and Assisted Reproductive Technologies, Al-Nahrain University. All rabbits were maintained during the study ( established at May 2014 to May 2015) with appropriate temperature and good ventilation. Animals were kept on fresh diet and allowed for free access to water. The experiment were approved by Animal Ethical Committee, College of Medicine, Al-Nahrain University, Baghdad, Iraq.

\section{Induction of cataract}

The rabbits were anesthetized by intramuscular injection of $0.5 \mathrm{ml}$ of $(50 \mathrm{mg} / \mathrm{ml})$ ketamine. In addition, lidocaine solution (2\%) was applied locally on the eye to obtain additional anesthetization. The induction of cataract in the right eye was done by a single intravitreal injection of $0.1 \mathrm{ml}$ from of sodium selenite solution $(0.01 \% \mathrm{w} / \mathrm{v})$. After injection, the rabbits were monitored every day for caractogenesis $^{(9,10,11)}$.

\section{Preparation of nimodipine eye drops $\mathbf{1 0 . 5 \%}$ w/v)}

A 500mg of nimodipine powder (reference standard from Bayer Schering Pharma) and 1\% $(\mathrm{w} / \mathrm{v})$ of benzalkonium chloride were dissolved in $100 \mathrm{ml}$ of isotonic buffer solution ${ }^{(12)}$.

The right eye of rabbit were received nimodipine $(0.5 \%)$ eye drops twice daily for five days before cataract induction and 21 days after cataract induction, and left eyes were received distilled water for same time and frequency

\section{Lens opacity}

The score of lens opacity (by the use of ophthalmoscope grading criteria) was done in accordance with the classification of Kador (13) and Chylack ${ }^{(14)}$.

\section{Pupil diameter}

By using the pupil gauge, measuring of pupil diameter was done and the results would be presented in millimeter units ${ }^{(15)}$.

\section{Pupillary response to light}

The light reflex was examined by swinging flashlight to investigate a relative afferent papillary defect ${ }^{(16,17)}$.

\section{Corneal sensation}

Corneal sensation could be examined with wisp of cotton wool, which applied and moved from side to side ${ }^{(15)}$.

\section{Conjunctival redness}

It could be detected by examination of conjunctiva of both eyes ${ }^{(16)}$.

\section{Intraocular pressure (IOP measurement)}

IOP measurement were done by anesthetization the cornea with a local anesthetic ( $2 \%$ lidocaine hydrochloride), and "the foot plate of the tonometer is placed on the cornea $\left(90^{\circ}\right.$ on the pupil), a small force (weight) is applied to a central plunger, causing the part of the cornea beneath the plunger to displace inward. The scale reading taking from the tonometer is converted to the corresponding $\mathrm{mmHg}$ of tension by referring to a standard chart" ${ }^{(18)}$.

\section{Measurement of glutathione (GSH) and MDA level in aqueous humor of rabbit eyes}

Glutathione was measured in accordance with the method of Godin (17) regarding to the reaction of glutathione with 5,5-Dithiobis (2nitrobenzoic acid) (DTNB) at $\mathrm{PH}$ of 8 , the result was a colored complex which absorbed light at $412 \mathrm{~nm}$. The technique to find out the MDA level is based on the reality that, in acid medium, MDA reacts with thiobarbituric acid (TBA) to form a pink-colored MDA-TBA 
complex that exhibits an absorption maximum at $532 \mathrm{~nm}^{(20,21)}$.

\section{Histopathological study}

The rabbit lens samples fixed by gluteraldehyde (3\%) solution for 48 hours. Following washing, treatment with osmium tetra oxide (1\%) for 20 minute, washing, dehydration at $4 \stackrel{\circ}{\circ}$ and embedding, tissues capsules sectioned at (1 micron), these sections stained with solution $A(0.4 \%$ basic fucshin in $25 \%$ methanol) and $B$ (Prepared by mixing the same volumes of (azure II, methylene blue, $\mathrm{Na} 2 \mathrm{CO} 3$, absolute methyl alcohol) and examined microscopically ${ }^{(22)}$.

\section{Statistical methods}

The obtained quantitative data was introduced as mean \pm Standard error of mean (S.E.M.). In graphic presentation, only the means of these data (i.e. without S.E.M.) were presented. The significance of the differences between mean values was estimated by using paired and unpaired student's t- test accordingly. The obtained difference was considered to be not significant if $p$ value $>0.05$, significant if $(0.05$ $\geq p>0.01$ ) and highly significant if $p \leq 0.01^{(23)}$.

\section{Results}

Nimodipine (0.5\%) eye drops resulted in complete prevention of cataract development (Figure 1). There was no alteration in pupil diameter, positive response to light, no change in corneal sensation, no conjunctival redness. The mean \pm SEM of IOP of eyes of rabbits was represented in figure (2) and its associated table. Before administration of nimodipine eye drops $(0.5 \%)$ to right eyes of rabbits, the IOP of right and left eyes were comparable. After one day of nimodipine eye drops (0.5\%) administration to right eyes of rabbits, there was high significant decrease in the IOP of right eyes when compared to left eyes $(P$ value $=$
0.005). There was high significant decrease in the IOP of right eyes when compared to left eyes at first day of cataract induction (after five days of nimodipine eye drops (0.5\%) administration), ( $P=0.009)$ and there was high significant difference after one week $(P=0.004)$, after two weeks $(P=0.002)$ and after three weeks of cataract induction ( $\mathrm{P}=0.002)$.

The levels of GSH and MDA were measured at the end of the study in the aqueous humor of apparently normal, cataract and nimodipine $(0.5 \%)$ eye drops groups were shown in the figure (3) and figure (4). There was high significant difference between the level of GSH in aqueous humor of cataract group and in the aqueous humor of nimodipine eye drops group $(P=0.0001)$. There was highly significant difference between the level of MDA in aqueous humor of cataract group and in the aqueous humor of nimodipine eye drops group $(P=0.0001)$

\section{Histopathological study of rabbit lens}

The cytoplasm of normal eye was uniform, featureless, and it was stained homogenously as shown in figure (5A). In the lens of cataract group, there was thick darkly stained collectives inside the fiber which extended along the lens fiber, these aggregations characterize the insoluble proteins that build up and aggregate in the lens fiber which caused by the oxidative and sclerotic outcome of selenite on the lens proteins. These aggregations are surrounded by plain or lighter areas produced as a result of losing the cytoplasm its homogenous form as shown by figure (5B). Nimodipine (0.5\%) eye drops administration twice daily resulted in prevention of cataract development; and the longitudinal section of lens showed homogenous appearance and it looked like normal in its feature, figure $(5 \mathrm{C})$ 
Shakoor et al, Effect of Nimodipine (0.5\%) Eye Drops ....

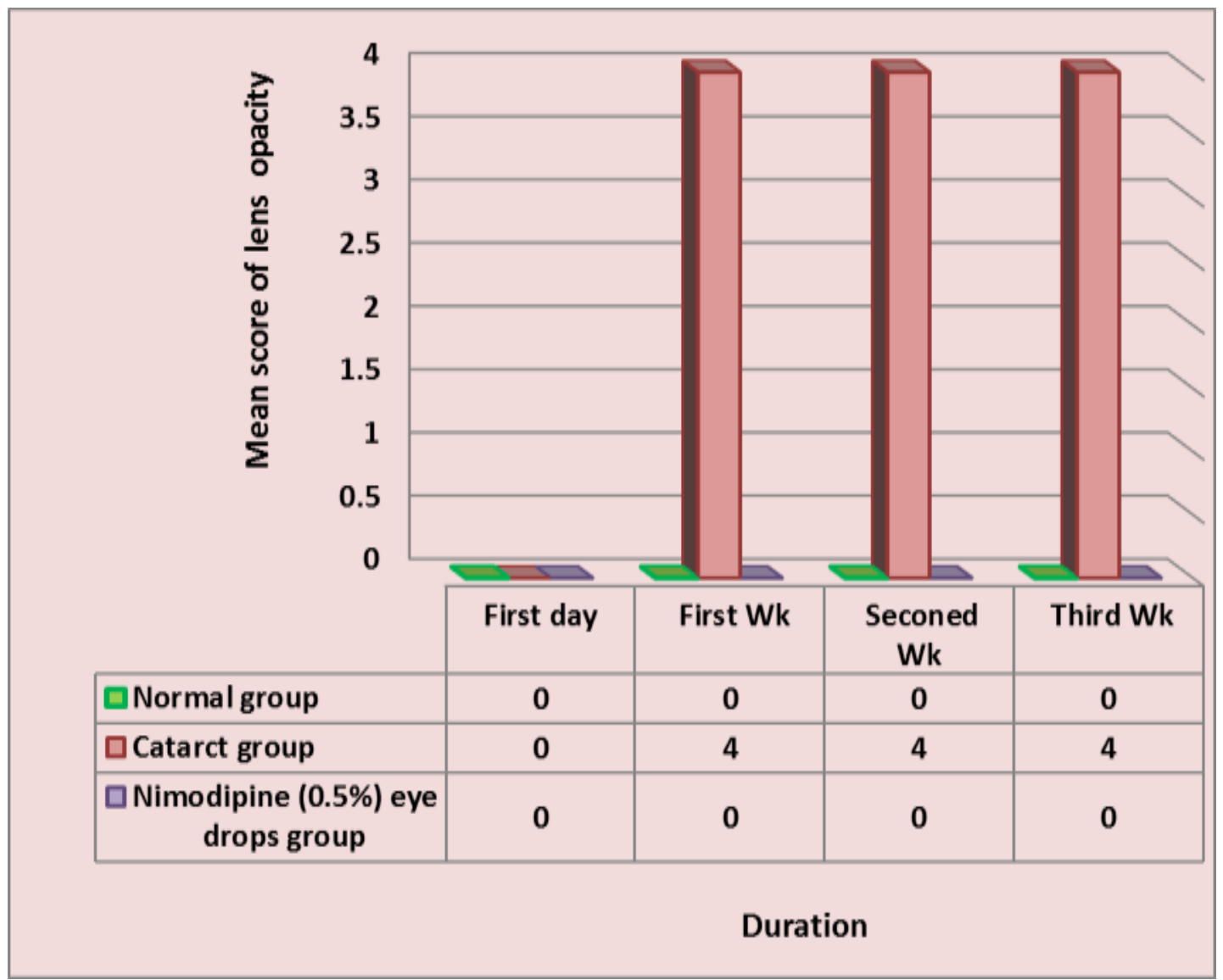

Fig. 1. Mean score of lens opacity in rabbits' right eyes of nimodipine eye drops group

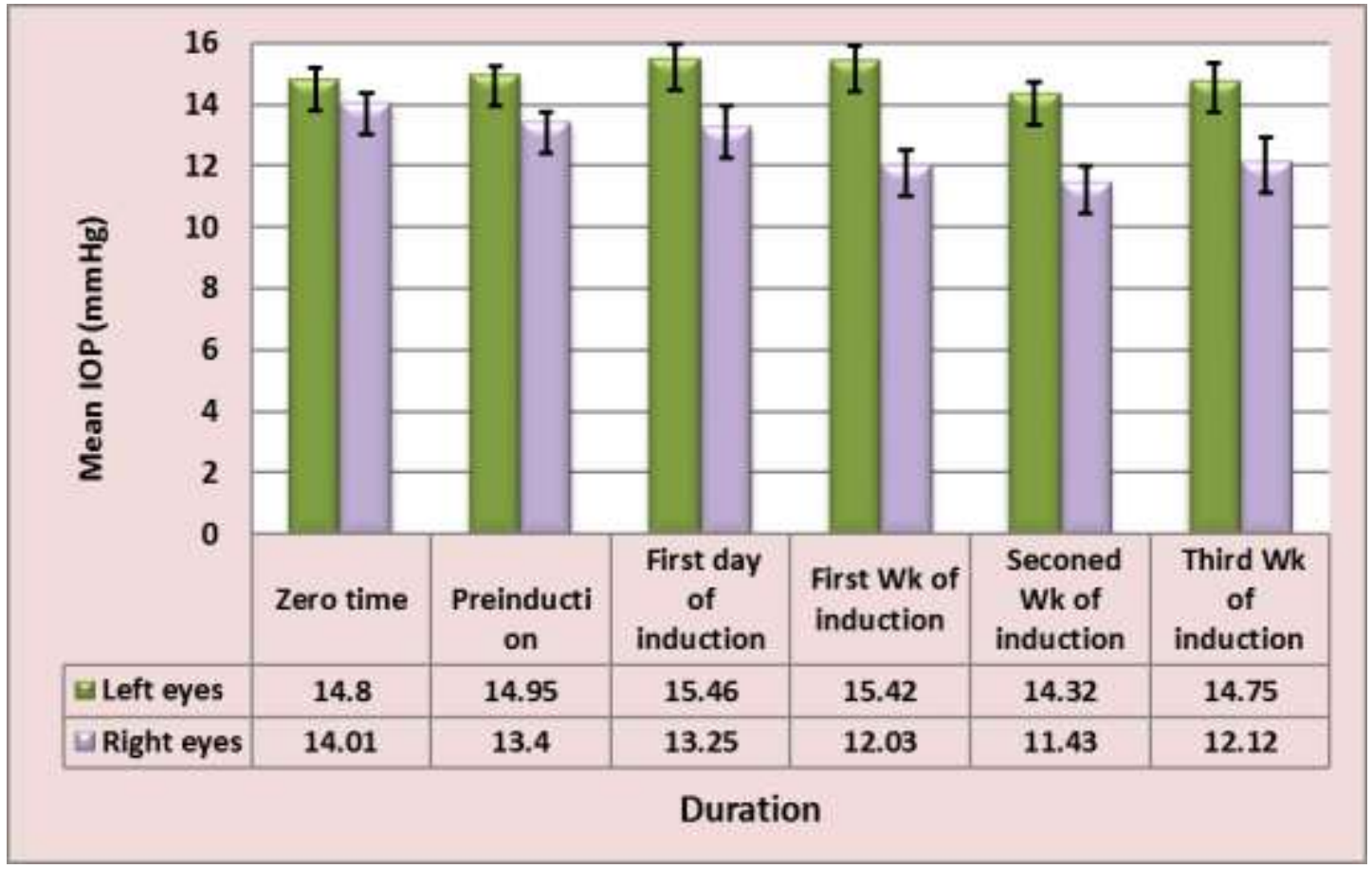

Fig. 2. Mean IOP of rabbits' eyes of nimodipine $(0.5 \%)$ eye drops group 
Iraqi JMS 2016; Vol. 14(3)

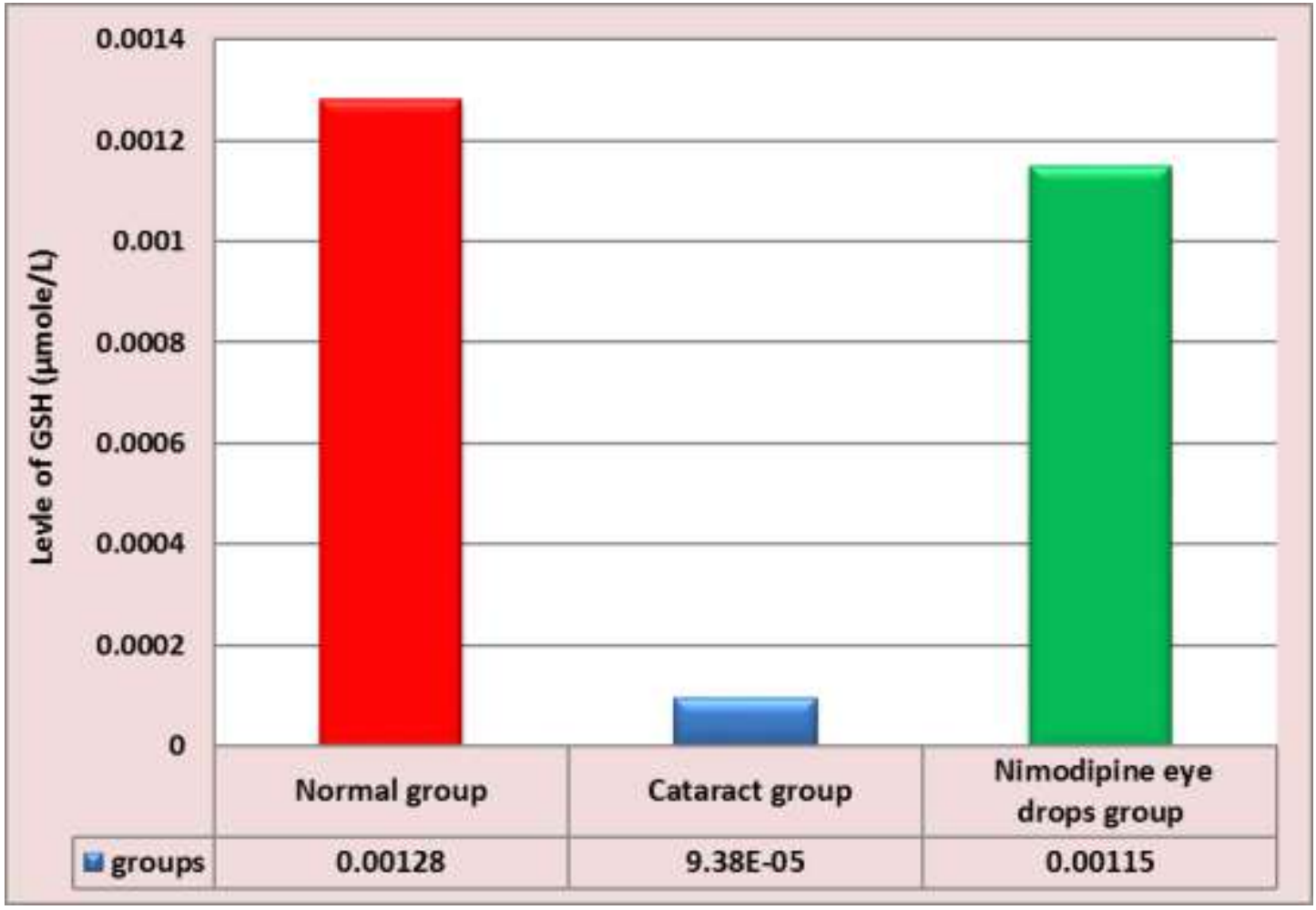

Fig. 3. Levels of GSH ( $\mu \mathrm{mol} / \mathrm{L}$ ) in aqueous humor of groups of study

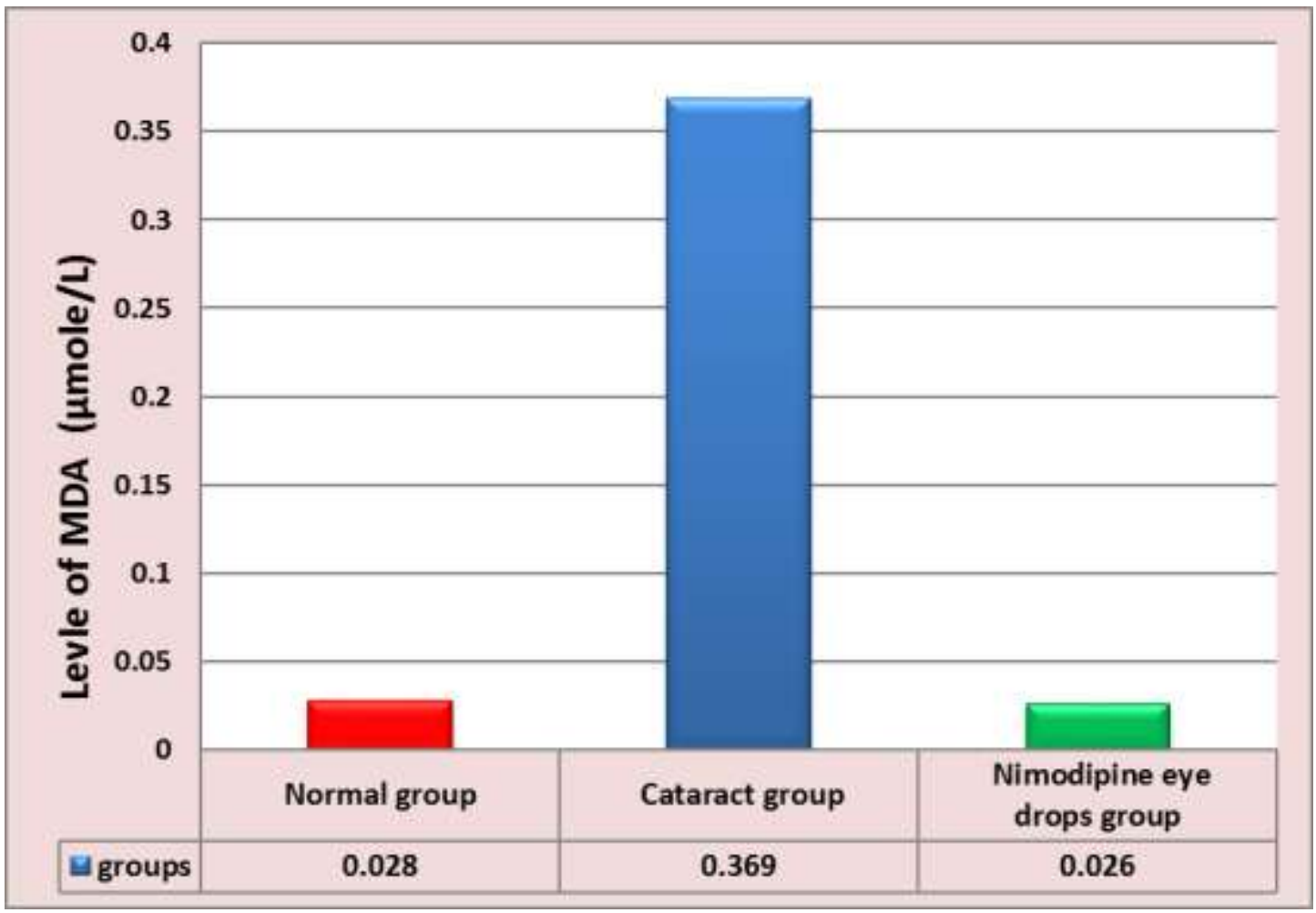

Fig. 4. Levels of MDA ( $\mu \mathrm{mol} / \mathrm{L}$ ) in aqueous humor of groups of study 


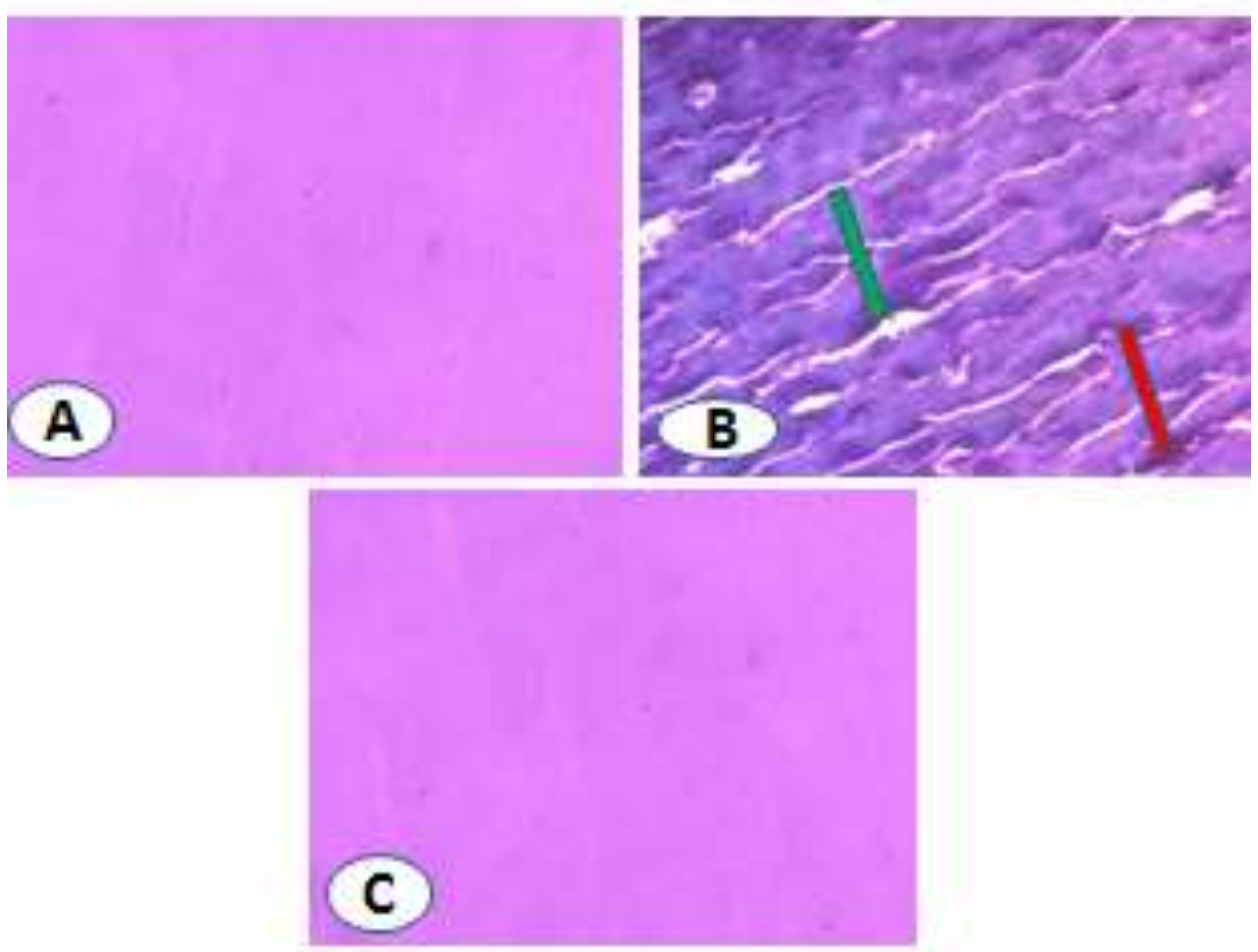

Fig. 5. Longitudinal section of rabbits' lens stained with solution A and B for semithin section (40X). A: Normal group shown homogenous cytoplasm of the normal lens fibers. B: Cataract group shown darkly stained aggregation (red arrows), alternating with clear areas (green arrows) with loss of the homogenous architecture of the cytoplasm of lens fibers. C: Nimodipine eye drops look like normal and shown structureless cytoplasm of lens fibers

\section{Discussion}

Nimodipine is a centrally active calcium channel blocker that blocks the voltage-dependent Ltype calcium channels ${ }^{(24)}$. "Intracellular $\mathrm{Ca}^{2+}$ overload triggers $\mathrm{Ca}^{2+}$ dependent lytic enzymes such as phospholipase-c that induce the release of free fatty acids (FFA) and xanthine oxidase. This leads to the generation of superoxide and the depletion of membrane phospholipids resulting in altered permeability and further $\mathrm{Ca}^{2+}$ influx ${ }^{(25)}$. The increase in the levels of $\mathrm{Ca}^{2+}$ in the human lenses with cataract had been found to play a main role in the opacification development ${ }^{(26)}$. The L-type calcium channel blocker (verapamil) was efficient in attenuating cataract formation in diabetic rats. Lenses extracted from animals, which had been treated with verapamil as well had a greatly decreased $\mathrm{Ca}^{2+}$ content. Other researches of diabetic and radiation models of cataract furthermore reported decreased lens opacification as a result of the treatment by L-type calcium channel blockers ${ }^{(27)}$. Variety of researches have revealed that calcium channel blockers may improve the ocular blood flow in the healthy volunteers and in patients with glaucoma28. Loss of $\mathrm{Ca}^{2+}$ homeostasis had been occupied in most types of cataract. $\mathrm{Ca}^{2+}$ levels are maintained in the sub$\mu \mathrm{M}$ range in cytoplasm by the membrane $\mathrm{Ca}^{2+}$ pumps, plasma membrane $\mathrm{Na}+/ \mathrm{Ca}^{2+}$ exchangers, and endoplasmic reticulum $\mathrm{Ca}^{2+}$ pumps (29). Increased $\mathrm{Ca}^{2+}$ uptake performed in correlation with selenite cataractogenesis, was established to be highest. A main consequence of calcium elevation in the lens is the activation of calpains. Researches on experimental cataract had demonstrated that calpain-induced proteolysis of $\beta$-crystallin was a major mechanism in lens maturation as well as cataractogenesis (30). Alterations of membrane proteins, lipid integrity, and consequent raise of the membrane ion permeability of lens fiber cells had been 
established in different pathological conditions. So, selenite-induced oxidative stress and subsequent loss of the $\mathrm{Ca}^{2+}$ homeostasis thought to be responsible for the activation of lens calpains, which led to in proteolytic precipitation and aggregation of insoluble proteins ${ }^{(31)}$.

This study concluded that Nimodipine (0.5\%) eye drops twice daily had protective effect against selenite induced cataract in rabbits' eyes.

\section{Acknowledgements}

We would like to express our deepest thanks and appreciation to Assisstant Prof. Dr. Bahaa A. Abdul Hussien, Assisstant Prof. Dr. Ahmed M. Rasheed and Prof. Dr. May Fadhil Majid for their great help.

\section{Author contribution}

The study was done by Dr. Shakoor under the supervision of Dr. Al-Zubaidy. Histopathological study was done with the assistance of Dr. Qasim.

\section{Conflict of interest}

The authors declare no conflict of interest

\section{Funding}

Self-funding.

\section{References}

1. Jacques PF, ChylackJr LT, Hankinson SE, et al. Longterm nutrient intake and early age-related nuclear lens olpacities. Arch Ophthalmol. 2001; 119: 1009-19.

2. Thylefors B, Negrel AD, Pararajasegaram R, et al. Global data on blindness. Bull World Health Org. 1995; 73: 115-21.

3. McCarty C, Taylor HR. Light and risk for age-related eye diseases. In: Taylor A. Nutritional and environmental influences on the eye. 1999. p. 135-50.

4. Delcourt C, Cristol JP, Tessier F, et al. The Pathologies Oculaires Lieersal' Age. Risk factors for cortical, nuclear, and posterior subcapsular cataracts: the POLA study. Am J Epidemiol. 2000; 151(5): 497-504.

5. Berendschot TT, Broekmans WM, Klopping-Ketelaars IA et al. Lens aging in relation to nutritional determinants and possible risk factors for age-related cataract. Arch Ophthalmol. 2002; 120: 1732-7.

6. Olmedilla B, Granado F, Blanco I, et al. Lutein, but not tocopherol, supplementation improves visual function in patients with age-related cataracts: a 2-y doubleblind, placebo-controlled pilot study. Nutrition. 2003; 19: 21-4.
7. Bennett PN, Brown MJ, Sharma P. Clinical pharmacology. $11^{\text {th }}$ ed. Elsevier Ltd. 2012; 151-60.

8. Cotlier E. Physiology of the lens. In: Moses RA, Hart WM. (eds.) Alder's Physiology of the eye - clinical application. $9^{\text {th }}$ ed. St. Louis: Mosby Company; 1995. p. 268-90.

9. Samuel J, Ziegler JR, Datlies MB. Pathogenesis of cataracts. In: Thomas M, Aaberg SR, Richard L, et al.(eds.) Duane's foundations of clinical ophthalmology. Philadelphia: Lippincott Williams \& Wilkins; 2003.

10. Abdulsahib WK and Al-Zubaidy AA. Effect of topically applied digoxin, nimodipine and sildenafil on ocular normotensive eyes of rabbits. M.S.c. thesis. College of medicine. Al-nahrian University; 2010. P.39-43.

11. Abdul-Hussein BA, Alzubaidy AA, Radi HA. Effect of diltiazem on intraocular pressure in normal and ocular hypertensive rabbits. QMJ; 2012: 8(13): 69-83.

12. British Pharmacopoeia. London, Her Masjesty's Stationary office, 2004; Vol. I.

13. Kador PF, Kinoshita JH. Diabetic and galactosaemic cataracts. Ciba Foundation Symposium. 1986; 106: 110-31.

14. Chylack LT, Leske MC, McCarthy D. Lens opacities classification system II (LOCS II). Arch Ophthalmol. 1989; 107: 991.

15. Ahuja M. Ophthalmology Handbook. $1^{\text {st }}$ ed. Delhi: India Binding House; 2003. p. 6-24, 145-163.

16. Jaffe NS, Jaffe MS, Jaffe GF. Cataract surgery and its complications. 5th ed. St. Louis: Mosby; 1990. p. 6-18.

17. Macdonald $M$. The examination of the eye. In: Munro J, Edwards C. Macleod's clinical examination. $10^{\text {th }}$ ed. Edinburgh: Churchill Livingstone; 2000. p. 257-71.

18. Moses RA. Intraocular pressure. In: Moses RA, Hart WM. Alder's Physiology of the eye clinical application. $9^{\text {th }}$ ed. St. Louis: Mosby Company, 1997. p. 223-45.

19. Godin DV, wahaieb SA, Garent ME. Antioxidant enzymes alteration in experimental and clinical diabetes. Mol Cell Biochem. 1988; 84: 223-31.

20. Stocks J, Dormandy TL. The auto-oxidation of human red cell lipids induced by hydrogen peroxide. $\mathrm{Br} \mathrm{J}$ Haematol. 1971; 20: 95-111.

21. Ohkawa H, Ohishi N, Yagi K. Assay of lipid peroxides in animal tissues by thiobarbituric acid reaction. Anal Biochem. 1979; 75: 351-8.

22. Al-Habib MF. Effects of aflatoxin B on some skeletal muscle resident cells using a nuclear differentiating stain technique. Iraqi J Med Sci. 2007; 5(2): 71-7.

23. Daniel WD, Cross CL. Biostatistics, a foundation for analysis in the health science. $10^{\text {th }}$ ed. New York: John Wiley and Sons Inc.; 2013. p. 223.

24. Nascimento VS, D'alva MS, Oliveira $A A$, et al. Antioxidant effect of nimodipine in young rats after pilocarpine-induced seizures. Pharmacol Biochem Behav. 2005; 82(1): 11-6.

25. Reilly PM, Schiller HJ, Bulkley GB. Pharmacological approach to tissue injury mediated by free radicals and 
Shakoor et al, Effect of Nimodipine (0.5\%) Eye Drops ....

other reactive oxygen metabolites. Am J Surg. 1991; 161: 488-503.

26. Rhodes JD, Sanderson J. The mechanisms of calcium homeostasis and signaling in the lens. Exp Eye Res. 2009; 88(2): 226-34.

27. Kametaka S, Kasahara $T$, Ueo M, et al. Effect of nifedipine on severe experimental cataract in diabetic rat. J Pharmacol Sci. 2008; 106: 651-8.

28. Niwa $Y$, Yamamoto $T$, Harris $A$, et al. Relationship between the effect of carbon dioxide inhalation or nilvadipine on orbital blood flow in normal-tension glaucoma. J Glaucoma.2000; 9: 262-267.

29. Kyselova Z. Different experimental approaches in modelling cataractogenesis. Interdiscip Toxicol. 2010: 3(1): 3-14.
30. David LL, Azuma M, Shearer TR. Cataract and the acceleration of calpain-induced $\beta$-crystallin insolubilization occurring during normal maturation of rat lens. Invest Ophthalmol Vis Sci. 1994; 35: 785-93.

31. Stitt AW. Advanced glycation: an important pathological event in diabetic and age-related ocular disease. Br J Ophthalmol. 2001: 85: 746-53.

Correspondence to Dalia A. Shakoor

E-mail: dalia.abdalkader@yahoo.com Received $4^{\text {th }}$ Apr. 2016: Accepted $5^{\text {th }}$ Jul.2016 